Available online at GSC Online Press Directory

GSC Biological and Pharmaceutical Sciences

e-ISSN: 2581-3250, CODEN (USA): GBPSC2

Journal homepage: https://www.gsconlinepress.com/journals/gscbps

(REVIEW ARTICle)

\title{
Green synthesis of pyranopyrazole using microwave assisted techniques
}

\author{
Bais Abhinav *, Chaple Dinesh, Asnani Alpana, Kumar Pratyush and Mohurle Shrikant \\ Priyadarshini J. L. College of Pharmacy, Electronic zone, Electronic building, Hingna Road, Nagpur-440016 \\ (Maharashtra), (India).
}

Publication history: Received on 28 January 2020; revised on 12 February 2020; accepted on 14 February 2020

Article DOI: https://doi.org/10.30574/gscbps.2020.10.2.0026

\begin{abstract}
The process of drug discovery involves the identification of lead molecule, synthesis, characterization, screening, assay for therapeutic efficacy. The Pyrano[2,3-c] pyrazole are important roles in the field of pharmacological and medicinal chemistry. The pyranopyrazole are important class of hetrocyclic ring prepared by a diverse range of synthetic procedure. The water as a green solvent is most enviormentally friendly, safe and inexpensive choice to decrese pollution, toxicity and cost of reaction. The Microwave irridation to eliminate the requirement of heat, enhance the rate of reaction and decreased total time is a widely applicable techinque and has been used for the synthesis of pyranopyrazole. The synthesis prepared by pyrazolone, aldehyde and malononitrile are allowed to react together under diffrent reaction condition to form a variety of pyranopyrazoles. The Pyranopyrazoles in general are biologically active and have remarkable antimicrobial, anticancer, anti-inflammatory, analgesic, antifungal etc.
\end{abstract}

Keywords: Drug discovery; Pyranopyrazole; Microwave irridation; Green synthesis; Biological activity.

\section{Introduction}

In the past most drugs have been discovered either by identifying the active ingredient from traditional remedies or by serendipitous discovery. The process of drug discovery involes the identification of lead molecules,synthesis, characterization, screening, assays for therapeutic efficacy. Once compound has shown its value in these tests, it will begin the process of drug development prior to clinical trials[1]

Pharmaceutical chemistry is the core branch of pharmacy education and research. It can be categorized as synthesis of new drug molecule, its analysis and pharmacological studies. The identification of sutiable lead which would forms a focal point around which a group of compound may be built.Search of therapeutially effective safer medicinal agents in treatment of various diseases in continued struggle since ages. Such searches is long process yielded potent and effective drugs.

The heterocyclic compounds are widely spread in nature and play an important role in life. Due to the characteristic properties, the heterocyclic compounds hold a large area in medicinal chemistry [2]. The chemistry of heterocyclic chemistry has been explored widely in the past two- three decades [3]. The synthesis and the application of heterocyclic compounds of medium size rings became popular [4,5]. During the recent years, there has been intense research on fused heterocyclic compounds with pharmacological importance. Among the heterocyclic of pyranopyrazole class has drawn the attention. Pyranopyrazoles refer to a fused five member pyrazole ring to a six member pyran ring. The pyranopyrazole nucleus is a versatile source of biologically important molecules. There are four possible isomers of pyranopyrazole-pyrano[2,3-c]pyrazole,pyrano[4,3-c]pyrazole, pyrano[3,2-c]pyrazole and pyrano[3,4-c]-pyrazole. The pyrano[2,3-c]pyrazoles (1) are the most popular with pharmacological importance and

\footnotetext{
${ }^{*}$ Corresponding author

E-mail address: abhinavbais1995@gmail.com
} 
have been explored most.Pyrano[2,3-c]pyrazolesposses important roles in the field of pharmacological and medicinal chemistry due to the various activities of the heterocyclic core.[6]

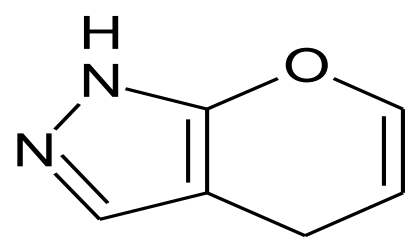

Figure 1 1, 4, -dihydropyrano[2,3-c] pyrazole

The pyrano[2,3-c]pyrazole derivatives are known in the literature since early 19th century. After the publication of Juneket al[7] in 1973 and Otto et al[8], tremendous developments have been done on the synthesis of functionalized pyrano[2,3-c]pyrazoles and its application in medicinal chemistry become popular. In this review pharmaceutically important and bioactive pyrano[2,3-c]pyrazoles are highlighted with their activities.Pyrazoles are five-membered heterocycles that constitute a class of compounds particularly usefulin organic synthesis. They are one of the most studied groups of compounds among the azole family. Indeed, a huge variety of synthesis methods and synthetic analogues have been reported over the years. The presence of the pyrazole nucleus in different structures leads to diversified applications in different areas such as technology, medicine and agriculture. In particular, they are described as inhibitors of protein glycation, antibacterial, antifungal, anticancer, antidepressant, antiinflammatory, anti-tuberculosis, antioxidant as well as antiviral agents. [9]

Nowadays, pyrazole systems, as biomolecules, have attracted more attention due to their

interesting pharmacological properties. This heterocycle can be traced in a number of well-established drugs belonging to different categories with diverse therapeutic activities. [10]

In this review, we present descriptions and discussions on the most relevant synthesis methods and pharmacological properties of pyrazole-derived heterocyclic systems.

Pyranopyrazoles are an important class of heterocyclic ring systems, which can be prepared by a diverse range of synthetic procedures,[11] have important pharmacological properties,[12-13] been the topic of theoretical studies,[14] and are of industrial significance.[15,16] Out of four possible isomeric forms, pyrano[2,3-c]pyrazole (2), pyrano[4,3-c]pyrazole (3), pyrano[3,2-c]pyrazole (4) and pyrano[3,4-c]pyrazole (5). The synthesis, derivatization and biological activities of a range of derivatives of 2 have been reported (Figure 2). [11, 12]<smiles>c1coc2nncc-2c1</smiles>

pyrano[4,3-c]pyrazole

(2)<smiles>c1coc2cnnc-2c1</smiles>

pyrano[3,2-c]pyrazole<smiles>c1cc2nncc-2co1</smiles>

pyrano[4,3-c]pyrazole

Figure 2 Structures of isomeric pyranopyrazoles 
The first synthesis of pyrano[2,3-c]pyrazoles (2) was reported by Stollé, who prepared it from hydrazine and ethyl acetoacetate.[13] Wolff also reported its synthesis at about the same time.[14] In 1973, Junek and Aigner synthesized some polynitrile derivatives of pyrano[2,3-c]pyrazoles which initiated developments in functionalized pyranopyrazoles synthesis such as pyrano[2,3-c]pyrazol-6-one (6), pyrano[2,3-c]pyrazol-4-one (7) and 4Hpyrano[2,3-c]pyrazole (8) (Figure 2). Khan and co-workers also synthesized various derivatives of $\mathbf{6}$ and 7. [15,16]<smiles>[R]C1=N[N+]([R7])=C2OC(=O)CC([R])C12</smiles><smiles>[R]C1=CC(=O)C2C([R])=N[N+]([R7])OC12</smiles><smiles>[R]C1=N[N+]([R7])OC2C([R7])=C([R])C([Al])C12</smiles>

Figure 3 Derivatives of pyranopyrazoles

\section{Synthesis of Pyrano[2,3-c] pyrazoles}

\subsection{Two component synthesis of Pyrano[2,3-c]pyrazoles}

Junek and Aigner treated tetracyanoethylene with pyrazol-5-one and 5-aminopyrazole to obtain pyrano[2,3c]pyrazoles (9), pyrazolo[3,4-b]pyridines (10) anddipyrazolylmalonodinitriles (11) respectively depending on reaction condition (Figure 4).[15] 6-Amino-1,3-disubstituted-4,4-5-tricyanopyrano[2,3-c]pyrazole (9) was obtained by refluxing the appropriate pyrazolone and tetracyanoethylene in ethanol.<smiles>[R7]c1nn([R7])c2c1C(C#N)C(C#N)=C(N)O2</smiles>

(9)<smiles>[R]NC1=C(C#N)C(C#N)c2c([R])nn([R])c2N1</smiles>

(10)<smiles>[R]N/C=C(/O)C(C(=O)O)C(C#N)C1C=NN=C1O</smiles>

(11)

$$
\begin{gathered}
\text { Yield 72\% } \\
\text { R1 = H, Ph } \\
\text { R2 = Ph, CO2Et }
\end{gathered}
$$

$$
\begin{aligned}
& \text { Yield 63-92\% } \\
& \text { R1 = Ph, CHMe2 } \\
& \text { R2 }=\mathrm{H}, \mathrm{Me}
\end{aligned}
$$

Yield 72\%

$\mathrm{R}=\mathrm{Ph}, 4-\mathrm{Me}-\mathrm{Ph}$

$\mathrm{R} 3=\mathrm{H}, \mathrm{COMe}$

Figure 4 Derivatives of pyranopyrazoles

Otto refluxed 4-benzylide-pyrazol-5-one (12) with malononitrile (13) in methanol in the presence of sodium acetate catalyst to obtain pyrano[2,3-c]pyrazole (14)[18] (Scheme 1).<smiles>[R11]C(C#N)C(=O)O</smiles>

(12)<smiles>[R7]C1=NN([R])C(=O)C1C([Al])C([Al])C(C)C</smiles>

(13)<smiles>[R7]c1nn([R])c2c1C([Al])C(C#N)C(N)O2</smiles>

(14)

Scheme No 1 
Wang et al. developed an efficient synthesis of 6-hydroxy-6-trifluoromethyl-pyrano[2,3-c]pyrazoles (17) in excellent yields (85-99\%) using $10 \mathrm{~mol} \%$ of 1,4-diazobicyclo[2.2.2]octane (DABCO) as base in DCM solvent at room temperature.[19] Other bases such as triethylamine, 1,8-diazabicyclo[5.4.0]undec-7-ene (DBU), 4dimethylaminopyridine (DMAP), $\mathrm{N}-\mathrm{N}$-dimethylaniline $\left(\mathrm{C} 6 \mathrm{H} 5 \mathrm{~N}\left(\mathrm{CH}_{3}\right)_{2}\right.$ were also tested in different solvents. All bases showed good results, but $20 \mathrm{~mol} \%$ of DABCO was found to be an excellent catalyst to provide diastereoselective control in the formation of pyranopyrazoles (6:1-30:1). X-Ray crystallographic analysis of the major isomer indicated that the trans-products were predominantly formed (Scheme 2).<smiles>[R]C(=O)C1C(O)OC(N)=C(C#N)C1O</smiles>

(15)<smiles>CC(C)(C)COC(=O)CONN</smiles>

(16)<smiles>[R]c1n[nH]c2c1C(Br)C(C#N)=C(N)O2</smiles>

(17)

$\mathrm{R}^{1}=$ ph.me, 4-Br.ph, $\mathrm{Ch}_{2}-\mathrm{ph}$

$\mathrm{Ar}=\mathrm{Ph}, 2-\mathrm{Me}-\mathrm{Ph}, 3-\mathrm{Me}-\mathrm{ph}, 4-\mathrm{meo}-\mathrm{ph}, 4-\mathrm{cl}-\mathrm{ph}$

$\mathrm{R}^{2}=\mathrm{Me}, \mathrm{CF}_{3}, \mathrm{Ph}, 4-\mathrm{Br}, 4-\mathrm{meo}-\mathrm{ph}$

\section{Scheme No 2}

Water as a green solvent, is the most environmentally friendly, safe and inexpensive choice to decrease pollution, toxicity and cost of a reaction.[20] Peng and co-workers used pure aqueous media for reaction of 5- alkoxycarbonyl-2amino-4-aryl-3-cyano-6-methyl-4H-pyrans (18) and hydrazine hydrate in the presence of a catalytic quantity of piperazine by three methods (i) heating (ii) exposing to microwave irradiation (iii) exposing to a combination of microwave and ultrasound irradiation where, the latter was found to be excellent in terms of yield within short time. [21] It was assumed that powerful ultrasound irradiation causes cavitations and high-velocity interparticle collisions, which cleaned the surface, thus mass transfer between two phases increased and the reaction completed fast without need of any organic co-solvent (Scheme 3).

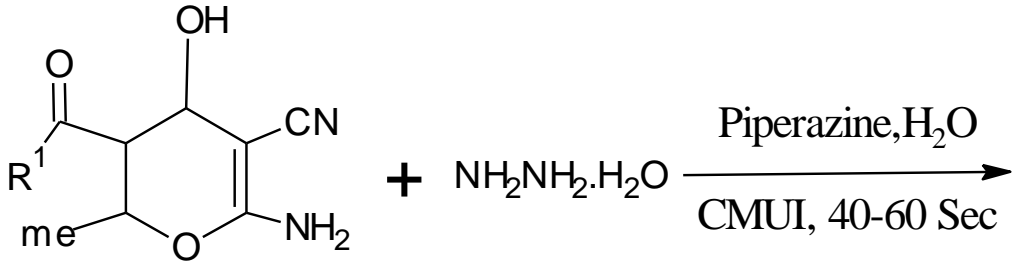

(18)<smiles>[R]c1n[nH]c2c1C(Br)C(C#N)=C(N)O2</smiles>

(19)

$$
\begin{aligned}
& \mathrm{R}^{1}=\mathrm{OET} \\
& \mathrm{R}=\mathrm{me}
\end{aligned}
$$$$
\mathrm{Ar}=\mathrm{ph}, 4-\mathrm{Meo}-\mathrm{ph}, 4-\mathrm{cl}-\mathrm{Ph}, 2-\mathrm{cl}-\mathrm{ph}
$$

\section{Scheme No 3}

Abdou and co-workers, in a simple procedure, refluxed various alkene derivatives $\mathbf{2 1}$ and pyrazolones in piperidine containing ethanolic solution to produce a variety of pyranopyrazoles bearing carbonitrile, hydroxyl or a phenyl group at the 6-position[22] (Scheme 4). 


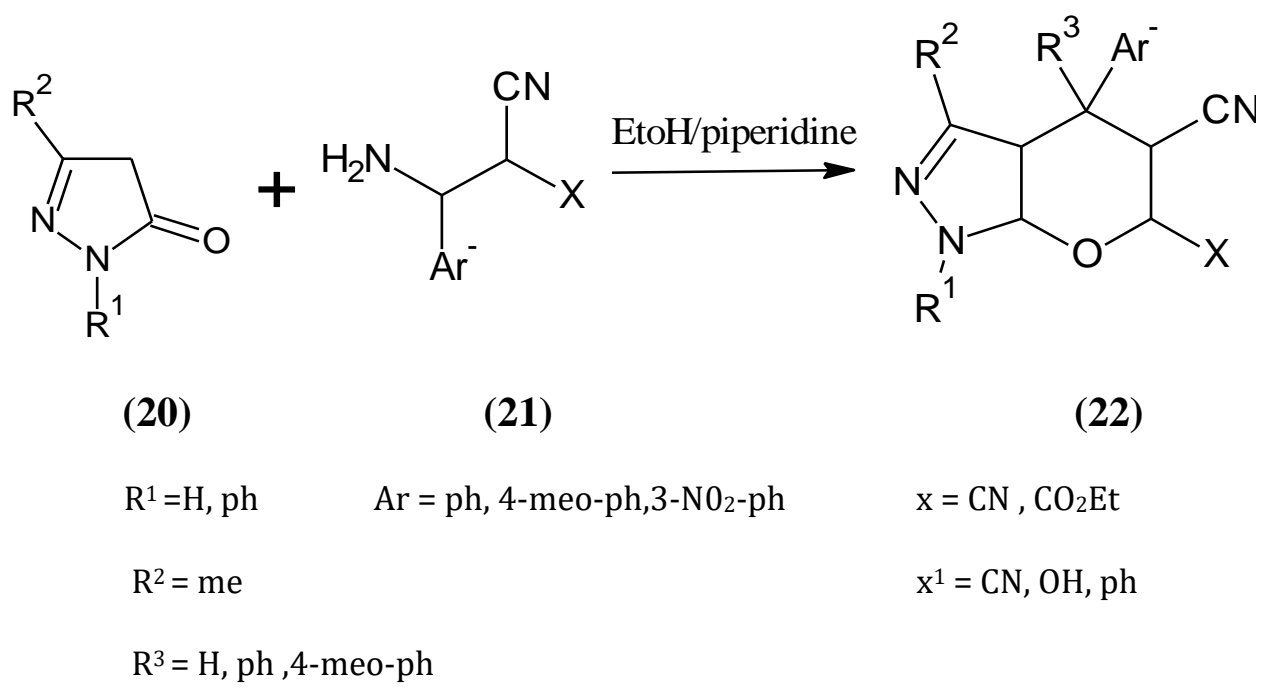

\section{Scheme No 4}

\subsection{Three components synthesis of Pyrano[2,3-c]pyrazoles}

Most of these examples used pyrazolone, aldehydes and malononitrile and allowed to react together under different reaction conditions to form a variety of pyranopyrazoles. Jin and co-workers added $p$-dodecylbenzenesulfonic acid (DBSA), as phase transfer catalyst, for uniform dispersion of reactants to get a better yield (84-94\%). [23] Initially, the reaction was tested in the absence of catalyst and yielded traces of product or no product as in case of 4dimethylaminobenzaldehyde, which has strong electron donating dimethylamino group that has significant contributions of the quinoid resonance form, hence reactivity decreased 23-24(Figure 5).

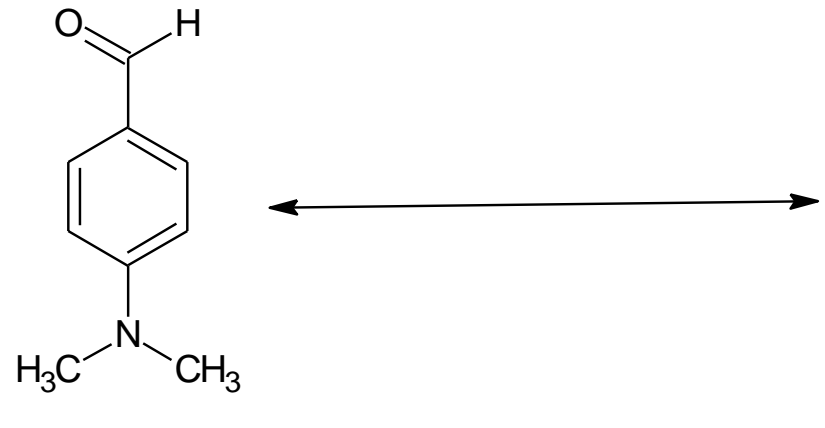

(23)<smiles>C[N+](C)=C1C=CC(=CO)C=C1</smiles>

(24)

Figure 5 Synthesis of Pyrano[2,3-c]pyrazoles in absence of catalyst

In another attempt, various PTC namely, TBAB, DBSA, sodium dodecyl sulphate (SDS) and HTMAB were tested for similar reactants where HTMAB was found best in term of yield [24]. The reaction conditions worked equally for aromatic aldehydes with electron-withdrawing and donating substituents, but did not proceed for aliphatic aldehydes probably, due to their low reactivity. Prajapati and co-workers refluxed substituted aldehydes, malononitrile and 1(2,4-dinitrophenyl)-3-methylpyrazol-5-one in ethanol containingpiperidine catalyst to give the respective pyranopyrazoles which were found to be good antibacterial agents.[25] 
<smiles>[R7]C1=NN([R7])C2OC(N)=C(C#N)C([Al])C12</smiles>

Scheme No 5

Table 1 Derivatives compound

\begin{tabular}{|c|c|c|c|c|c|}
\hline Scheme & R1 & $\mathbf{R 2}$ & Ar & Condition & Yield \\
\hline A & $\mathrm{Ph}$ & $\mathrm{CH} 3$ & $\begin{array}{l}\text { Ph,4-me-ph, 4-meo- } \\
\text { ph,2-cl-ph }\end{array}$ & $\begin{array}{l}\mathrm{H} 2 \mathrm{o} \text {, DBSA, } 10 \mathrm{~mol} \% \\
, 60^{\circ} \mathrm{C}, 3 \text { hours }\end{array}$ & $84-94 \%$ \\
\hline B & $\mathrm{Ph}$ & $\mathrm{CH} 3$ & $\mathrm{Ph}, 2$-cl-ph, 3-cl-ph & $\begin{array}{ll}\text { H2o, } 10 & \text { mol } \%, \\
\text { HTMAB, } & 85-90^{\circ} \mathrm{C}\end{array}$ & $79-92 \%$ \\
\hline $\mathrm{C}$ & 2-4,dinitro-ph & $\mathrm{CH} 3$ & $\mathrm{Ph}, 4$-cl-ph, 2-cl-ph, & $\begin{array}{l}\text { EtoH, Piperidine, } \\
\text { Reflux } 3 \text { hours }\end{array}$ & $70-76 \%$ \\
\hline
\end{tabular}

Pyranopyrazoles bearing a triflouromethyl group at the 3-position were obtained by reaction of aldehydes, malononitrile and trifluoromethylpyrazol-5-one, in water as solvent without catalyst at $90^{\circ} \mathrm{c}$, in good yields in 3-5 $\mathrm{h}$ (Scheme $6 \mathrm{~A}$ ).[26] The yield of the product is not affected by the electronic nature of the aryl substituents. Bhavanarushi and co-workers prepared flouropyranopyrazoles by grinding similar reactants in a pestle mortar using DBU as catalyst and established the molecular mechanism for DNA binding of resultant products (Scheme 6 B) [27]. Microwave irradiation to eliminate the need of heat, enhances the rate of reaction, is a widely applicable technique and has been used for the synthesis of pyranopyrazoles within 2-8 min in dry ethanol containing piperidine catalyst (Scheme 6 C).[28] Diaminopyrano[2,3-c]pyrazoles were prepared at room temperature in ethanolic solvent containing secondary amine/organic bases such as pyridine, piperidine and pyrrolidine.[29] The resultant compounds were found to be potential antibacterial agent while, some of them also exhibited antifungal activity (Scheme 6 D).<smiles>[R]C1CC(=O)N([Tl])N1</smiles>

Scheme No 06 
Table 2 Derivatives compound

\begin{tabular}{llllll}
\hline Scheme & $\mathbf{R}^{\mathbf{1}}$ & $\mathbf{R}^{\mathbf{2}}$ & $\mathrm{Ar}$ & Condition & Yield \\
\hline $\mathrm{A}$ & $\mathrm{Ph}$ & $\mathrm{CF}_{3}$ & $\mathrm{Ph}, 4-\mathrm{cl}-\mathrm{ph}$ & $\mathrm{H}_{20}, 90^{\circ} \mathrm{c}, 3-5 \mathrm{hrs}$ & $78-90 \%$ \\
$\mathrm{~B}$ & $\mathrm{Ph}$, 3-cl-ph & $\mathrm{CF}_{3}$ & $\mathrm{Ph}, 4-\mathrm{No}_{2}-\mathrm{ph}$, & $\mathrm{DBU}$, grinding at RT & $81-88 \%$ \\
$\mathrm{C}$ & $\mathrm{Ph}$ & $\mathrm{Me}$ & $\mathrm{Ph}, 4-\mathrm{cl}-\mathrm{ph}$, & Piperidine/EtoH & $61-91 \%$ \\
$\mathrm{D}$ & $\mathrm{Ph}$ & $\mathrm{NH}_{2}$ & $\mathrm{Ph}, 2-\mathrm{cl}-\mathrm{ph}$, & EtoH, RT & $64-90 \%$ \\
& & & & & \\
\hline
\end{tabular}

\section{Biological activities}

Pyranopyrazoles in general are biologically active and have remarkable antimicrobial, anticancer, anti-inflammatory, analgesic, anticonvulsant, anti-platelet, vasodilator, antifungal, potential Chk1 inhibitor, herbicidal16 and molluscicidal properties. Moreover, pyranopyrazoles were found to be effective inhibitors to steel corrosion6 and as antioxidants for lubricant oil.

Since these can lead to a variety of pyrano[2,3-c]pyrazoles by virtue of aryl and hetaryl aldehydes, hydrazines and malononitriles and other reactants, the researchers from time to time have subjected the novel synthesized compounds to diverse type of biological activities which may be summed up in the following:

Tetrahydroquinolines derivatives being biological active anti-HIV, antibacterial, antifungal, antimalarial, antitrypanosomal, antitumor, psychotropic, anti-allergic, anti-inflammatory, and estrogenic agents, were incorporated with pyranopyrazoles to obtain potential biologically active compounds.

\section{Conclusion}

This review summarizes the synthesis of pyrano[2,3-c]pyrazoles which, either have a hydrogen atom at 4-position or condensed spiro group. Synthesis focuses on two component or multi-component reactions including three, four and/or five reactants. Reactions conditions are variable including green approach, nanoparticulates, heteropolyacid, reflux temperature, room temperature, organic catalyst, microwave and ultrasonic irradiations. Most common reagents for synthesis are pyrazolone, benzylide, hydrazine, $\beta$-ketoesters, malononitrile, aldehydes and ketones. Various substituted phenyl, polynuclear naphthalene, anthracene as well as number of heterocyclic moiety such as furan, thiophene, indole, tetrahydroquinoline have been incorporated at 4-position. Most of the pyrano[2,3c]pyrazoles have amino and cyano groups at sixth and fifth position respectively, but some shows variations and have hydrogen, aryl or other group. Compounds are reported as antibacterial, antifungal, anti-oxidant, anti inflammatory, anti-ulcerogenic, anti-analgesic, anticonvulsant and insecticidal agents. X-Ray studies done to confirm the structure and position of hydrogen atom in the pyrazolone ring.

\section{Compliance with ethical standards}

\section{Acknowledgments}

The authors gratefully acknowledge the support provided by Principal and HOD and Teaching Staff of Priyadarshini J.

L. College of Pharmacy, Nagpur.

\section{Disclosure of conflict of interest}

The authors declare that there are no conflicts of interest. 


\section{References}

[1] Christian GD. (2006). Analytical Chemistry, Fifth edition, John Wiley and Sons, Singapore, 340.

[2] Pozharskii Af, Sodatemkov At and Kartritzky Ar. (1997). Heterocycles in Life and Society: An Introduction to Heterocyclic Chemistry, Biochemistry and Applications, Second Edition, 6(4), 301.

[3] Jug K, Oricine Dc and Katritzky Ar. (2001). Quantitative Measures of Aromaticity for Mono-, Bi-, and Tricyclic Penta and Hexaatomic Hetero aromatic Ring Systems and Their Interrelationships, Chemistry Review, (101), 1421-1450.

[4] Elnagdi Mh, Elmoghayar Mrh and Sadek Ku. (1987).Chemistry of Pyrazolopyrimidines, Department of Chemistry, Faculty of Science, Cairo University, Giza, Egypt. Advance Heterocyclic Chemistry, 41, 314.

[5] Elnagdi Mh, Elmoghayar Mrh and Sadek. Ku. (1990). Chemistry of Pyrazolopyrimidines, Department of Chemistry, Faculty of Science, Cairo University, Giza, Egypt. Advance Heterocyclic Chemistry, 48, 223.

[6] Abdelrazek FM, Metz P, Jäger A and Metwally NH. (2017). An Ecofriendly Synthesis of Some Novel 4-methyl-4-hetaryl Chromene and Pyrano[2,3-c ]pyrazole Derivatives. Journal of Heterocyclic Chemistry, 54 (4), 2313-2318.

[7] Junek H and Aigner H. (1973). Reaktionen von Tetracyanathylen rnit Heterocyclen, Institute for Organic Chemistry, Graz, A-8010. Flemrichstr, Chemische Berichte, 106, 914-921.

[8] Otto HH. (1974). Diversity Oriented Synthesis of Pyrano[2,3-c]pyrazoles and their Characterization. Arch Pharm Chemistry of Life Science, 307(6), 444-447.

[9] Fustero S, Sánchez-Roselló M, Barrio P and Simón-Fuentes A. (2011). From 2000 to Mid-2010: A fruitful decade for the synthesis of pyrazoles. Chemical Reviews, Acs Publication, 111, 6984-7034.

[10] Ansari A, Ali A and Asif M. (2017). Biologically active Pyrazole Derivatives. New Journal of Chemistry, 41, 1641.

[11] Myrboh B, Mecadon H, Rohman M, Rajbangshi M, Kharkongor I, Laloo B, Kharbangar I and Kshiar B. (2013). Organic Preparation and Procedures International Journal for Organic Synthesis, 45(4), 253-303.

[12] Fadda A, El-Mekabaty A and Elattar K. (2013). Chemistry of Enaminonitriles of pyrano[2,3-c]pyrazole and Realated compound. An International Journal for Rapid Communication of Synthetic Organic Chemistry, 43(20), 2685-2719.

[13] Stolle R. (1905). Ueber die Cozdensation von Acetessigoater mit Phengl-methyl-pyrazolon und die Einwirkungsproducte von Phenylhydrazin und Hydrazin auf Dehydracetsaure. European Journal of Organic Chemistry, 38(3), 3023-3032.

[14] Wolff L. (1905). Ueber das Azin des Aceteasigesters. European Journal of Organic Chemistry, 38(3), 3036-3041.

[15] Junek H and Aigner H. (1973). Synthesen mit Nitrilen, Reaktionen von Tetracyanäthylen mit Heterocyclen. Journal of CHEMISCHE BERICHET, 106(3), 914-921.

[16] Khan MA, Cosenza AG and Ellis GP. (1982). Synthesis and Reactions of 1H, 6H-pyrano [2, 3-c]pyrazole-6-ones. Journal of Heterocyclic Chemistry, 19, 1077-1085.

[17] Khan MA, Ellis GP and Pagotto MC. (2001). Pyranopyrazoles III Synthesis of 1H-Pyrano [2, 3-c]pyrazol-4-ones. Journal of Heterocyclic Chemistry, 38(1), 193-197.

[18] Otto HH. (1974). Diversity Oriented Synthesis of Pyrano [2,3-c]pyrazoles and their Characterization. Arch Pharm Chemistry of Life Science, 307(6), 444-447.

[19] Wang J, Huang GB, Yang LJ, Li F, Nie J and Maa JA. (2015). Tandem Stereoselective Synthesis of New Trifluoromethylated Pyranopyrazoles. Journal of Fluorine Chemistry, 171, 27- 35.

[20] Smith R. (2006).Superheated water: the ultimate green solvent for separation science. Analytical and Bioanalytical Chemistry, 385(3), 419-421.

[21] Peng Y, Song G and Dou R. (2006). Surface cleaning under combined microwave and ultrasound irradiation: flash synthesis of 4H-pyrano [2, 3-c]pyrazoles in aqueous media. Journal of Green Chemistry, 8(6), 573-575. 
[22] Abdou S, Fahmy SM, Sadek KU and Elnagdi. (1981). Activated nitriles in heterocyclic synthesis: a novel synthesis of pyrano [2, 3-c pyrazoles. An International Journal for Reviews and Communications in Heterocyclic Chemistry, 16(12), 2177 - 2180.

[23] Jin TS, Zhao RQ and Li TS. (2006). An one-pot three-component process for the synthesis of 6-amino-4-aryl-5cyano-3-methyl-1-phenyl-1, 4-dihydropyrano [2,3-c]pyrazoles in aqueous media. Archive for Organic Chemistry, 11, 176-182.

[24] Jin TS, Wang AQ, Cheng ZL, Zhang JS and Li TS. (2005). A Clean and simple synthesis of 6-Amino-4-Aryl-5-cyno3-methyl-1-phenyl-1, 4-dihydropyrano[2,3-c]pyrazole in water. An International Journal for Rapid Communication of Synthetic Organic Chemistry, 35(1), 137-143.

[25] Prajapati SP, Patel DP and Patel PS. (2012). Phenylboronic acid-catalyzed a four component synthesis of pyrano[2,3-c] pyrazole derivatives in aqueous media: an eco-friendly method . Journal of Chemical and Pharmaceutical Research, 4, 2652-2655.

[26] Yu C, Yao C, Li T and Wang, X. (2014). An aqueous, catalyst-free and three-component synthesis of 6-amino-3(trifluoromethyl)-1,4-dihydro1-phenyl-4-arylpyrano[2,3-c]pyrazole-5-carbonitriles. Research on Chemical Intermediates, 40(4), 1537-1544.

[27] Bhavanarushi S, Kanakaiah V, Yakaiah E, Saddanapu V, Addlagatta A and Rani. (2013). Synthesis, cytotoxic, and DNA binding studies of novel fluorinated condensed pyrano pyrazoles. Journal Medicinal Chemistry Research, 22(5), 2446-2454.

[28] Zhou JF, Tu SJ and Zhu HQ Zhi. (2002). a facile one pot synthesis of pyrano[2,3-c]pyrazole derivatives under microwave irradiation. An International Journal for Rapid Communication of Synthetic Organic Chemistry, 32, 3363-3366.

[29] Katariya LK and Kharadi GJ. (2014). A Facile One Post Synthesis of Pyrano[2,3-c] Pyrazoles with Implement of Various Basic Catalysts and its Biological Evaluation. International Journal for Pharmaceutical Research Scholars, 3, 627-637.

\section{How to cite this article}

Bais A, Chaple D, Asnani A, Kumar P and Mohurle S. (2020). Green synthesis of pyranopyrazole using microwave assisted techniques. GSC Biological and Pharmaceutical Sciences, 10(2), 111-119. 